\title{
EXTENSIONS OF LEMOS-SOARES TYPE LOG-MAJORIZATION
}

\author{
ZESHENG FENG AND JiAn SHI*
}

Abstract. In this paper, we shall obtain extensions of Lemos-Soares log-majorization via Furuta inequality.

Mathematics subject classification (2020): 47A63.

Keywords and phrases: log-majorization, $\alpha$-power mean, Furuta inequality.

\section{REFERENCES}

[1] T. Ando And F. HiaI, Log majorization and complementary Golden-Thompson type inequalities, Linear Algebra Appl., 197 (1994), 113-131.

[2] H. ArAKI, On an inequality of Lieb and Thirring, Lett Math Phys., 19 (1990), 167-170.

[3] M. FujiI AND E. KAMEI, Ando-Hiai inequality and Furuta inequality, Linear Algebra Appl., 416 (2006), 541-545.

[4] T. FurutA, $A \geqslant B \geqslant 0$ assures $\left(B^{r} A^{p} B^{r}\right)^{1 / q} \geqslant B^{(p+2 r) / q}$ for $r \geqslant 0, p \geqslant 0, q \geqslant 1$ with $(1+2 r) q \geqslant$ $p+2 r$, Proc. Amer. Math. Soc., 101 (1987), 85-88.

[5] E. HeinZ, Beiträge zur Störungstheorie der Spektralzerlegung, Math. Ann., 123 (1951), 415-438.

[6] F. Kubo And T. Ando, Means of positive linear operators, Math. Ann., 246 (1980), 205-224.

[7] R. Lemos AND G. SOARES, Some log-majorizations and an extension of a determinantal inequality, Linear Algebra Appl., 547 (2018), 19-31.

[8] R. Lemos And G. Soares, Spectral inequalities for Kubo-Ando operator means, Linear Algebra Appl., 607 (2020), 29-44.

[9] C. LöWnER, Über monotone Matrixfunktionen, Math. Z., 38 (1934), 177-216.

[10] Y. SEo And M. Tominaga, A complement of the Ando-Hiai inequality, Linear Algebra Appl., 429 (2008) 1546-1554. 